\title{
MATING PREFERENCES AND SEXUAL SELECTION IN THE ARCTIC SKUA
}

\author{
P. O'DONALD, N. S. WEDD and J. W. F. DAVIS \\ Department of Genetics, University of Cambridge, Milton Road, Cambridge CB4 1XH
}

Received 21.viii.73

\begin{abstract}
SUMMARY
The relationship between breeding time and fitness in the Arctic skua is described in terms of a fitness function estimated from the empirical data. There is no significant variation in the fitness function between pairs who have bred together for different numbers of years. Sexual selection takes place between the different colour phases of males, for among new pairs the palephased males breed later on average and with a greater variance in breeding time than the dark and intermediate males. The sexual selective coefficients were calculated from the fitness function using the distributions of breeding times of males in new pairs. Pale males have a relative disadvantage of 0.07 and intermediates a relative disadvantage of 0.03 compared to dark males. The overall selective coefficients calculated from the empirical values of the fitness of all pairs are $0 \cdot 18$ and $0 \cdot 16$ for pale and intermediate males respectively. There is no significant evidence for selection between different phases of females. Models of the mechanism of sexual selection by female mating preferences are fitted to the distributions of breeding time. About 50 per cent of females must exercise mating preferences to maintain the differences observed. The predictions of the models are discussed in relation to the data at present available.
\end{abstract}

\section{INTRODUCTION}

The Arctic skua is a sea bird that breeds in colonies from the North of Scotland up into the Arctic Circle. It is polymorphic with pale, intermediate and dark phases in its populations. The frequencies of the phases form a cline with pale phases generally more abundant in the northern parts of the range and dark phases more abundant in the southern parts. It breeds monogamously, though about 15 per cent of birds mating together for the first time change their mates in the next breeding season. After a pair have bred together for 2 or 3 years, however, they then normally stay together.

The colony of Arctic skuas on Fair Isle in the Shetlands has been intensively studied for many years. The colour phases of the birds, their breeding time and breeding success and their changes of mate were recorded in detail. The data, which have already been partially analysed (O'Donald, 1962, 1972a, b, c; Berry and Davis, 1970), suggest that sexual selection may favour the darker males. Because the Arctic skua is monogamous, sexual selection cannot take place simply as a result of the favoured males mating with more females than the others. To gain an advantage in a monogamous species, a sexually favoured male must mate with a female who will bear him more offspring. Darwin (1871) put forward a subtle theory of how this could happen. He suggested that the females who are the first to breed at the start of the breeding season do so because they are in 
a better nourished state than the others who breed later. For the same reason they would also be able to rear more and fitter offspring. The variation in the breeding condition of females would depend on how well they had survived the previous winter. The males who gained an advantage would then be those whom the females preferred to mate with. Or by direct competition with other males for territories, they might have the first choice of the females who were ready to breed. Thus they would gain a selective advantage by mating with the earlier females who would then bear them more offspring. O'Donald (1962) showed that, as Darwin's theory requires, clutch size and fledging success are greater among the earlier pairs of Arctic skuas. He later analysed the data (O'Donald, 1972a) in terms of a "fitness function" of the relationship between breeding time, measured by the date of hatching of the first chick, and fitness, measured by the number of chicks a pair managed to fledge successfully. A computer model of Darwin's theory, using the fitness function calculated for the breeding times of the Arctic skua, showed that the sexual selection is necessarily frequency-dependent. It is positively frequency-dependent if most of the females have a mating preference for a particular male phenotype: the selective advantage of the favoured males then increases as they increase in frequency. But if only a few of the females have mating preferences, the selection is negatively frequency-dependent, the selective advantage declining as the favoured males increase and spread through the population.

Berry and Davis (1970) in their analysis of the data showed that among pairs breeding together for the first time darker males tend to breed earlier: dark males breed on average before the intermediates who breed before the pales. There is no significant difference, however, between the mean breeding times of the different phases of female. O'Donald (1972c) used Berry and Davis's values of the means and variances of the different phases of males to calculate the selective coefficients of the sexual selection, assuming the fitness function was the same for all pairs. If the dark-phased males are given a relative fitness of one and a selective coefficient of zero, the selective coefficients of intermediates and pales, measured relative to the darks, are 0.13 and 0.34 respectively. Since new pairs are about 36 per cent of all pairs the overall selective coefficients of intermediates and pales are 0.047 and $0 \cdot 12$ by this calculation.

In this paper, the whole of the data, collected on Fair Isle, is fully analysed to determine the variation in both breeding times and fitnesses among the males and females of the different phases. The results are used to test O'Donald's models of sexual selection. Models of specific mating preferences by which the males are sexually selected are also tested by fitting them to the distributions of breeding times of newly mated pairs.

\section{The origin of the Fair IsLe data}

The skuas on Fair Isle were first studied by K. Williamson when he became Warden of the Fair Isle Bird Observatory. Williamson (1965) gives a general account of Fair Isle and its birds. P. E. Davis, who became Warden in 1957, continued the study. From 1958 to 1960, he was assisted by P. O'Donald who was then a research student supported by a Nature Conservancy Studentship. O'Donald (1962) in his Ph.D. thesis analysed the data he had helped to collect and it was from these data that the fitness 
function of breeding time, used in the computer models, was calculated (O'Donald, 1972a). R. J. Berry very generously made available to us his tabulation of all the original data from Fair Isle. The data were then coded for storage on a disk-file in the Titan Computer of the University of Cambridge.

\section{The FITNESS FUnGTION OF BREEDING TIME}

In order to calculate the mean fitnesses of different phenotypes, which are determined by their different distributions of breeding times, the overall relationship between breeding time and fitness must be known. Table 1 shows the empirical relationship between the breeding time given by the

TABLE 1

Overall distribution of fitness in relation to breeding time

\begin{tabular}{|c|c|c|c|c|c|}
\hline $\begin{array}{c}\text { Breeding } \\
\text { dates }\end{array}$ & \multicolumn{3}{|c|}{$\begin{array}{c}\text { No. of pairs fledging } \\
0,1 \text { or } 2 \text { chicks }\end{array}$} & \multirow{2}{*}{$\begin{array}{l}\text { Mean } \\
\text { fitness }\end{array}$} & \multirow{2}{*}{$\begin{array}{l}\text { Variance } \\
\text { per pair } \\
0.40960\end{array}$} \\
\hline $11-15$ & 2 & 8 & 15 & & \\
\hline 16 & 0 & 6 & 17 & 1.7391 & $0 \cdot 19282$ \\
\hline 17 & 0 & 9 & 17 & 1.6538 & $0 \cdot 22633$ \\
\hline 18 & 1 & 10 & 17 & 1.5714 & $0 \cdot 31633$ \\
\hline 19 & 0 & 7 & 17 & 1.7083 & $0 \cdot 20660$ \\
\hline 20 & 3 & 13 & 21 & 1.4865 & 0.41198 \\
\hline 21 & 0 & 6 & 21 & 1.7778 & 0.17284 \\
\hline 22 & 2 & 11 & 10 & 1.3478 & 0.40076 \\
\hline 23 & 3 & 17 & 33 & 1.5660 & 0.35885 \\
\hline 24 & 2 & 10 & 12 & 1.4167 & 0.40972 \\
\hline 25 & 1 & 10 & 8 & $1 \cdot 3684$ & 0.33795 \\
\hline 26 & 0 & 7 & 17 & 1.7083 & $0 \cdot 20660$ \\
\hline $27-28$ & 2 & 9 & 18 & 1.5517 & 0.38526 \\
\hline $29-30$ & 2 & 7 & 12 & 1.4762 & 0.43991 \\
\hline $31-32$ & 6 & 15 & 11 & $1 \cdot 1562$ & 0.50684 \\
\hline $33-36$ & 6 & 11 & 9 & $1 \cdot 1154$ & 0.56361 \\
\hline $37-40$ & 6 & 19 & 1 & 0.8077 & 0.23225 \\
\hline \multirow[t]{2}{*}{$41-48$} & 8 & 11 & 2 & 0.7143 & 0.39456 \\
\hline & 44 & 186 & 258 & 1.4385 & \\
\hline
\end{tabular}

number of days after the lst of June when the first egg hatched and the fitness given by the average number of chicks fledged by pairs breeding at a given date. Hatching date is the most satisfactory measure of breeding time, for other possible measures like laying date are more difficult to determine accurately.

A quadratic equation can be fitted to data on breeding times and fitnesses as described by O'Donald (1972a). A convenient quadratic equation is

$$
w=1-a-K(\theta-x)^{2}
$$

where $w$ is the mean fitness of individuals breeding at time $x$. At $x=\theta$, $w$ is at its maximum value of $1-\alpha$. The mean and variance in fitness can be found in terms of parameters $\alpha, K$ and $\theta$ and the moments of the distribution of $x$. For relative fitnesses with a maximum at $w=1$, we may put $\alpha=0$ giving the relative fitness function

$$
w=1-(\theta-x)^{2} / \phi
$$


where $\phi=1 / K$. The mean relative fitness is therefore given by

$$
\bar{w}=1-(\theta-\bar{x})^{2} / \phi-V_{x} / \phi
$$

where $V_{x}$ is the variance of $x$. O'Donald (1972a) obtained the function $w=1-(0.473544-x)^{2} / 24 \cdot 254$ for the relative fitness of pairs breeding in weekly intervals starting with the week 10-16 June. This function was used to calculate the sexual selective coefficients of the colour phases (O'Donald, 1972c). It fits the data given in table 1 very well: $\chi^{2}=2 \cdot 38$ for 4 degrees of freedom.

Although the fitness function is a good fit to the overall data, there may be significant variations in fitness between pairs who have bred together for different numbers of years. The pairs can be classified by their breeding experience, given by the number of years they have previously bred together. It is clear from earlier work (O'Donald, 1962) that new pairs with no experience together breed much later on average than pairs who have several years of previous experience breeding together. The new pairs produce fewer offspring. This may be a result solely of their later breeding; or they may produce fewer offspring even when they breed at the same time as experienced pairs. If their reduced fitness is solely caused by their late breeding, then the overall fitness function can be used to calculate the coefficients of sexual selection operating on new pairs. If not, a separate fitness function valid for new pairs would have to be used.

In order to compare the fitnesses of pairs with different breeding experience, it is necessary to group the data into weekly intervals. Even so, there are hardly any individuals with several years' experience in the last interval. Table 2 shows the values of the fitness in those intervals in which there were enough pairs to provide reasonable estimates of fitness. When there were too few pairs of greater experience they were lumped with those of less experience as the table shows. The mean fitness in each interval is simply the mean number of chicks reared by the total number of pairs in each interval. Heterogeneity of fitness with experience is tested by $\chi^{2}$. Given the number of pairs of different experience in an interval, the number of chicks they are expected to produce can be calculated from the mean fitness of all pairs in the interval (assuming the null hypothesis that in a given interval there is no variation of fitness with experience). $\chi^{2}$ cannot be calculated, however, by the simple formula

$$
\chi^{2}=\Sigma \frac{(\text { observed }- \text { expected nos. })^{2}}{\text { expected nos. }}
$$

because each observed number of chicks is not a simple Poisson variate with a variance equal to the expected number. The variance is determined by the overall numbers of pairs who fledge zero, one or two chicks. Thus in any interval the fitness of individual pairs takes the values $w=0,1$ or 2 . If the proportions of pairs with these fitnesses are $p, q$ and $r$ (so that $p+q+r=1$ ) then the variance in the fitness of a single pair can be calculated as follows:

$$
\begin{aligned}
& \text { fitness, } w \quad 0 \quad 1 \quad 2 \\
& \text { proportion of pairs } \quad p \quad q \quad r \\
& \bar{w}=q+2 r \\
& V_{w}=q+4 r-(q+2 r)^{2} \\
& =p q+4 p r+q r \text {. }
\end{aligned}
$$




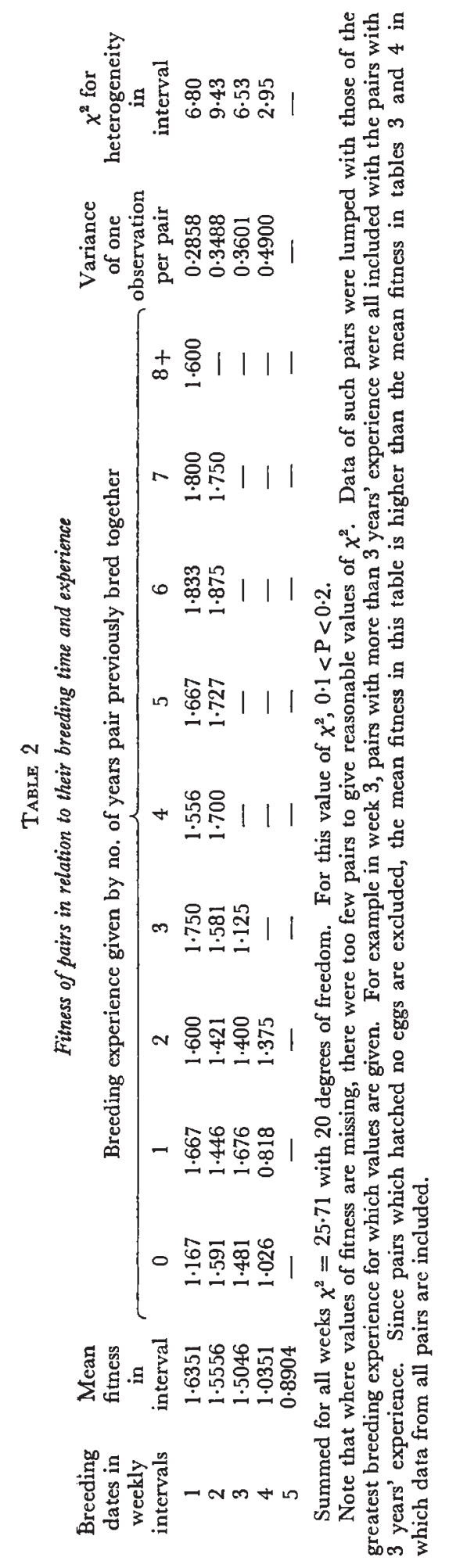


The values of the variance given in table 2 were calculated in this way. For $n$ pairs the variance is $V_{w}=n(p q+4 p r+q r)$. Thus we calculate

$$
\chi^{2}=\Sigma \frac{(\text { observed }- \text { expected nos. })^{2}}{\text { variance }}
$$

This calculation gives the values of $\chi^{2}$ for heterogeneity shown in table 2 . They are not significant.

\section{The COefFicients of SEXUAL SELECTION}

The data were analysed by computer to give the means and variances of breeding times and fitnesses in each of the phases and in different groupings of the phases in relation to breeding experience and sex. The results are shown in table 3 for males and in table 4 for females. The second column in the tables, headed "year", refers to the number of years pairs have been breeding together.

This analysis of breeding times is more detailed than Berry and Davis's analysis and more data are included, but the results are similar. In pairs breeding together for the first time, dark males breed on average before dark-intermediate males who breed before intermediate males who in turn breed before pale males. There is a similar sequence in the variances, the pale males being much the most variable in breeding time and the dark males the least variable. But these differences between the phases almost completely disappear in pairs breeding for 2 or more years together. And no such differences are found between phases in females. These facts strongly suggest that sexual selection favours the darker males. Sexual selection can only take place when pairs mate for the first time. If the females prefer the darker males or if the darker males compete more successfully for the females, then the distribution of breeding times of the darker males should have an earlier mean and a smaller variance than the distribution of the paler males. But these differences in the distributions of breeding times should disappear after the first year of breeding. Table 3 shows that there are no significant differences in the means and variances of the breeding times of the phases after the first year.

Given the means and variances of the breeding times, the fitnesses of the different phases can be calculated from the fitness function. Thus O'Donald (1972c) obtained the following values of the sexual selective coefficients. measuring the relative disadvantage of intermediate and pale males:

$$
\begin{aligned}
s_{I} & =0.13 \\
s_{P} & =0.34
\end{aligned}
$$

From the data given in this paper, the sexual selective coefficients can be calculated directly from the empirical fitnesses given in table 1 . The breeding times of new pairs of males are shown in fig. 1. The fitnesses of these pairs taken from table 1 give the average fitnesses of the different phases of males. in new pairs. For pale males $w_{P}=1.0980$; for intermediate and darkintermediate males $\bar{v}_{I}=1.2641$; and for dark males $\bar{w}_{D}=1.3635$. The sexual selective coefficients are therefore:

$$
\begin{aligned}
s_{I} & =0.0729 \\
s_{P} & =0.195 .
\end{aligned}
$$


TABle 3

Males

Breeding date

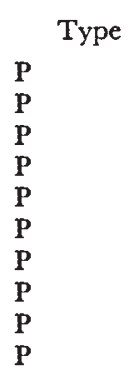

Year
1
2
3
4
5
6
7
8
9
10

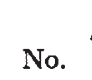

26

16

$$
11
$$$$
8
$$$$
\begin{aligned}
& 8 \\
& 4
\end{aligned}
$$$$
4
$$

3

2

2

\section{NOTP}

NOTP

NOTP

NOTP

NOTP

NOTP

NOTP

NOTP

NOTP

NOTP

I
I
I
I
I
I
I
I
I
I

I \& DI

I \& DI

I \& DI

I \& DI

I \& DI

I \& DI

I \& DI

I \& DI

I \& DI

I \& DI

DI
DI
DI
DI
DI
DI
DI
DI
DI
DI

1
2
3
4
5
6
7
8
9
10

1
2
3
4
5
6
7
8
9
10

$\begin{array}{rr}146 & 29 \cdot 062 \\ 94 & 24 \cdot 383 \\ 58 & 22 \cdot 845 \\ 41 & 20 \cdot 610 \\ 24 & 19 \cdot 167 \\ 19 & 18 \cdot 105 \\ 9 & 18 \cdot 222 \\ 5 & 16 \cdot 600 \\ 2 & 12 \cdot 500 \\ 1 & 16 \cdot 000\end{array}$

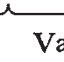

$\begin{array}{lc}\text { Mean } & \text { Variance } \\ 33 \cdot 923 & 90 \cdot 554 \\ 25 \cdot 062 & 17 \cdot 796 \\ 22 \cdot 818 & 24 \cdot 364 \\ 20 \cdot 875 & 25 \cdot 268 \\ 24 \cdot 250 & 8 \cdot 250 \\ 22 \cdot 500 & 25 \cdot 667 \\ 24 \cdot 000 & 39 \cdot 000 \\ 20 \cdot 500 & 24 \cdot 500 \\ 18 \cdot 500 & 4 \cdot 500 \\ 18 \cdot 000 & 0\end{array}$

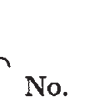

No. chicks fledged

No.

Mean $\underbrace{}_{\text {Variance }}$

$37 \quad 0.703 \quad 0.604$

22

13

11

1.091

0.604
0.753

1.385

0.423

1.091

2.000

$0 \cdot 691$

1.750

0

$1 \cdot 667$

$2 \cdot 000$

$1 \cdot 333$

0.250

0.333

0

$1 \cdot 333$

0.500

\begin{tabular}{|c|c|c|c|}
\hline $56 \cdot 803$ & 211 & 0.948 & 0.688 \\
\hline $32 \cdot 949$ & 116 & $1 \cdot 310$ & 0.581 \\
\hline $27 \cdot 572$ & 73 & 1.315 & 0.413 \\
\hline 19.094 & 46 & $1 \cdot 435$ & 0.473 \\
\hline $20 \cdot 667$ & 30 & $1 \cdot 400$ & 0.524 \\
\hline $15 \cdot 544$ & 20 & 1.550 & 0.471 \\
\hline 6.944 & 12 & $1 \cdot 750$ & 0.386 \\
\hline $9 \cdot 300$ & 7 & $1 \cdot 429$ & 0.619 \\
\hline 4.500 & 3 & $1 \cdot 667$ & 0.333 \\
\hline 0 & 1 & $1 \cdot 000$ & 0 \\
\hline
\end{tabular}

$\begin{array}{rcc}57 & 30 \cdot 614 & 59 \cdot 170 \\ 36 & 26 \cdot 611 & 36 \cdot 359 \\ 26 & 23 \cdot 615 & 19 \cdot 286 \\ 15 & 22 \cdot 933 & 24 \cdot 352 \\ 10 & 21 \cdot 200 & 32 \cdot 622 \\ 7 & 18 \cdot 143 & 6 \cdot 143 \\ 3 & 18 \cdot 333 & 8 \cdot 333 \\ 2 & 19 \cdot 000 & 18 \cdot 000 \\ 0 & 0 & 0 \\ 1 & 16 \cdot 000 & 0\end{array}$

$\begin{array}{rll}90 & 0.811 & 0 \cdot 672 \\ 48 & 1.083 & 0 \cdot 674 \\ 29 & 1.310 & 0.436 \\ 17 & 1.235 & 0 \cdot 691 \\ 12 & 1 \cdot 417 & 0 \cdot 811 \\ 7 & 2 \cdot 000 & 0 \\ 4 & 1 \cdot 750 & 0 \cdot 250 \\ 3 & 1 \cdot 667 & 0 \cdot 333 \\ 1 & 1 \cdot 000 & 0 \\ 1 & 1.000 & 0\end{array}$

92

$\begin{array}{cc}29 \cdot 707 & 62 \cdot 034 \\ 25 \cdot 463 & 36 \cdot 442 \\ 23 \cdot 371 & 24 \cdot 711 \\ 21 \cdot 739 & 23 \cdot 202 \\ 20 \cdot 286 & 25 \cdot 912 \\ 17 \cdot 556 & 6 \cdot 028 \\ 17 \cdot 400 & 5 \cdot 800 \\ 17 \cdot 667 & 14 \cdot 333 \\ 0 & 0 \\ 16 \cdot 000 & 0\end{array}$

$\begin{array}{rll}134 & 0.873 & 0.668 \\ 68 & 1.279 & 0.622 \\ 40 & 1.300 & 0.421 \\ 26 & 1.346 & 0.555 \\ 17 & 1.294 & 0.721 \\ 9 & 1.778 & 0 \cdot 194 \\ 6 & 1.833 & 0 \cdot 167 \\ 5 & 1.400 & 0.800 \\ 1 & 1.000 & 0 \\ 1 & 1.000 & 0\end{array}$

$28 \cdot 700$
$24 \cdot 571$
$24 \cdot 667$
$20 \cdot 800$
$18 \cdot 667$
$15 \cdot 000$
$16 \cdot 000$
0
0
0

$64 \cdot 631$
$29 \cdot 956$
$54 \cdot 267$
$16 \cdot 700$
$4 \cdot 333$
0
0
0
0
0

$\begin{array}{rll}37 & 1 \cdot 027 & 0 \cdot 694 \\ 15 & 1 \cdot 800 & 0 \cdot 171 \\ 7 & 1 \cdot 000 & 0 \cdot 333 \\ 6 & 1 \cdot 333 & 0 \cdot 267 \\ 4 & 1 \cdot 000 & 0 \cdot 667 \\ 1 & 1 \cdot 000 & 0 \\ 1 & 2 \cdot 000 & 0 \\ 1 & 0 & 0 \\ 0 & 0 & 0 \\ 0 & 0 & 0\end{array}$




\begin{tabular}{|c|c|c|c|c|c|c|c|}
\hline \multirow[b]{2}{*}{ Type } & \multirow[b]{2}{*}{ Year } & \multirow[b]{2}{*}{ No. } & \multicolumn{2}{|c|}{ TABLE 3 (continued) } & \multirow[b]{2}{*}{ No. } & \multicolumn{2}{|c|}{ No. chicks fledged } \\
\hline & & & Mean & Variance & & Mean & Variance \\
\hline DI \& D & 1 & 70 & $28 \cdot 471$ & $53 \cdot 180$ & 96 & 1.073 & $0 \cdot 679$ \\
\hline $\mathrm{DI} \& \mathrm{D}$ & 2 & 42 & $22 \cdot 929$ & $23 \cdot 044$ & 50 & 1.520 & $0 \cdot 459$ \\
\hline DI \& D & 3 & 22 & $22 \cdot 136$ & $28 \cdot 314$ & 30 & $1 \cdot 300$ & 0.355 \\
\hline DI \& D & 4 & 20 & $19 \cdot 500$ & $12 \cdot 158$ & 22 & 1.545 & $0 \cdot 260$ \\
\hline $\mathrm{DI} \& \mathrm{D}$ & 5 & 12 & $18 \cdot 083$ & 8.992 & 15 & 1.467 & $0 \cdot 410$ \\
\hline DI \& D & 6 & 10 & $18 \cdot 000$ & $25 \cdot 556$ & 11 & $1 \cdot 273$ & $0 \cdot 618$ \\
\hline DI \& D & 7 & 4 & $18 \cdot 500$ & $11 \cdot 000$ & 6 & $1 \cdot 667$ & $0 \cdot 667$ \\
\hline DI \& D & 8 & 2 & $15 \cdot 000$ & 0 & 3 & $1 \cdot 000$ & $1 \cdot 000$ \\
\hline DI \& D & 9 & 2 & $12 \cdot 500$ & $4 \cdot 500$ & 2 & $2 \cdot 000$ & 0 \\
\hline $\mathrm{DI} \& \mathrm{D}$ & 10 & 0 & 0 & 0 & 0 & 0 & 0 \\
\hline $\mathrm{D}$ & 1 & 39 & $27 \cdot 974$ & $42 \cdot 815$ & 56 & $1 \cdot 107$ & $0 \cdot 679$ \\
\hline $\mathrm{D}$ & 2 & 28 & $22 \cdot 107$ & $18 \cdot 470$ & 33 & 1.455 & $0 \cdot 506$ \\
\hline $\mathrm{D}$ & 3 & 15 & $20 \cdot 867$ & $17 \cdot 552$ & 22 & $1 \cdot 364$ & $0 \cdot 338$ \\
\hline $\mathrm{D}$ & 4 & 14 & $19 \cdot 000$ & $11 \cdot 692$ & 15 & $1 \cdot 667$ & 0.238 \\
\hline $\mathrm{D}$ & 5 & 8 & $17 \cdot 625$ & 11.982 & 10 & 1.700 & 0.233 \\
\hline $\mathrm{D}$ & 6 & 8 & $17 \cdot 750$ & 27.929 & 9 & $1 \cdot 222$ & $0 \cdot 694$ \\
\hline $\mathrm{D}$ & 7 & 2 & $17 \cdot 500$ & $4 \cdot 500$ & 4 & 1.500 & 1.000 \\
\hline D & 8 & 2 & 15.000 & 0 & 2 & $1 \cdot 500$ & $0 \cdot 500$ \\
\hline D & 9 & 2 & $12 \cdot 500$ & $4 \cdot 500$ & 2 & $2 \cdot 000$ & 0 \\
\hline $\mathrm{D}$ & 10 & 0 & 0 & & 0 & 0 & 0 \\
\hline
\end{tabular}

These values are lower than those calculated by the fitness function but the differences are not statistically significant. They are not true selective coefficients, however, for they apply only to new pairs, which make up 36 per cent of all pairs. The mean selective coefficients resulting from the variation in fitness at breeding time are therefore:

$$
\begin{aligned}
s_{I} & =0.026 \\
s_{P} & =0.070 .
\end{aligned}
$$

These are the coefficients of sexual selection.

The overall differences in fitness between the phases can be calculated empirically. Tables 3 and 4 give a complete analysis of fitness by phase, sex and breeding experience. The mean fitnesses averaged over pairs with different breeding experience are shown in table 5. Most of the variation in fitness in the males comes from the new pairs and a considerable part of their variation in fitness is caused by their variation in breeding time and hence by sexual selection.

An analysis of variance of the differences in fitness can be carried out treating the pairs with different breeding experience as "blocks" in a randomised block experiment. For males we get the following mean squares (M.S.) :

$$
\begin{array}{ll}
\text { M.S. (between phases) } & =2.6538 \\
\text { M.S. (within phases and experience) } & =0.5774 \text {. }
\end{array}
$$

The variance ratio is $F=4.60$ which is significant at a probability of $P=$ $0 \cdot 01$. For females we obtain:

$$
\begin{array}{ll}
\text { M.S. (between phases) } & =0.6900 \\
\text { M.S. (within phases and experience) } & =0.5730
\end{array}
$$

and the variance ratio is not significant. 
Table 4

Females

\begin{tabular}{|c|c|c|c|c|c|c|c|}
\hline \multirow[b]{2}{*}{ Type } & \multirow[b]{2}{*}{ Year } & \multirow[b]{2}{*}{ No. } & \multicolumn{2}{|c|}{ Breeding date } & \multirow[b]{2}{*}{ No. } & \multicolumn{2}{|c|}{ No. chicks fledged } \\
\hline & & & Mean & Variance & & Mean & Variance \\
\hline $\mathbf{P}$ & 1 & 34 & $31 \cdot 471$ & $61 \cdot 105$ & 52 & $0 \cdot 692$ & 0.609 \\
\hline $\mathbf{P}$ & 2 & 28 & $24 \cdot 536$ & $26 \cdot 480$ & 33 & $1 \cdot 303$ & 0.655 \\
\hline $\mathbf{P}$ & 3 & 13 & $22 \cdot 462$ & $19 \cdot 936$ & 18 & $1 \cdot 278$ & 0.448 \\
\hline $\mathbf{P}$ & 4 & 13 & $19 \cdot 615$ & $19 \cdot 423$ & 14 & $1 \cdot 643$ & 0.401 \\
\hline $\mathbf{P}$ & 5 & 5 & $20 \cdot 000$ & $22 \cdot 500$ & 7 & 1.429 & 0.952 \\
\hline $\mathbf{P}$ & 6 & 6 & $18 \cdot 833$ & $31 \cdot 767$ & 6 & $1 \cdot 500$ & 0.300 \\
\hline $\mathbf{P}$ & 7 & 4 & $20 \cdot 500$ & $53 \cdot 667$ & 5 & $1 \cdot 400$ & $0 \cdot 800$ \\
\hline $\mathbf{P}$ & 8 & 1 & $16 \cdot 000$ & 0 & 2 & $2 \cdot 000$ & 0 \\
\hline $\mathbf{P}$ & 9 & 0 & 0 & 0 & 2 & $0 \cdot 500$ & 0.500 \\
\hline $\mathbf{P}$ & 10 & 1 & $16 \cdot 000$ & & 1 & $1 \cdot 000$ & 0 \\
\hline NOTP & 1 & 139 & $29 \cdot 345$ & $64 \cdot 605$ & 197 & 0.970 & 0.683 \\
\hline NOTP & 2 & 82 & $24 \cdot 463$ & $32 \cdot 375$ & 105 & $1 \cdot 267$ & 0.601 \\
\hline NOTP & 3 & 56 & $22 \cdot 929$ & $28 \cdot 613$ & 68 & $1 \cdot 338$ & 0.406 \\
\hline NOTP & 4 & 36 & $21 \cdot 028$ & $19 \cdot 685$ & 43 & $1 \cdot 279$ & 0.539 \\
\hline NOTP & 5 & 23 & $19 \cdot 870$ & $22 \cdot 664$ & 27 & $1 \cdot 481$ & 0.413 \\
\hline NOTP & 6 & 17 & $18 \cdot 882$ & $16 \cdot 360$ & 18 & $1 \cdot 611$ & 0.487 \\
\hline NOTP & 7 & 8 & $19 \cdot 250$ & $6 \cdot 214$ & 10 & 1.900 & $0 \cdot 100$ \\
\hline NOTP & 8 & 6 & 18.000 & $16 \cdot 000$ & 8 & 1.500 & 0.571 \\
\hline NOTP & 9 & 4 & $15 \cdot 500$ & $15 \cdot 000$ & 4 & $2 \cdot 000$ & 0 \\
\hline NOTP & 10 & 1 & $18 \cdot 000$ & 0 & 2 & $1 \cdot 500$ & 0.500 \\
\hline I & 1 & 74 & $29 \cdot 689$ & $65 \cdot 779$ & 104 & 0.990 & 0.709 \\
\hline I & 2 & 39 & $24 \cdot 359$ & $26 \cdot 236$ & 51 & $1 \cdot 294$ & 0.652 \\
\hline I & 3 & 29 & $23 \cdot 966$ & $29 \cdot 820$ & 34 & $1 \cdot 382$ & 0.365 \\
\hline I & 4 & 16 & $20 \cdot 500$ & $17 \cdot 333$ & 19 & $1 \cdot 316$ & $0 \cdot 561$ \\
\hline I & 5 & 7 & $18 \cdot 714$ & 20.571 & 10 & $1 \cdot 400$ & 0.489 \\
\hline I & 6 & 5 & $18 \cdot 800$ & $10 \cdot 700$ & 5 & $2 \cdot 000$ & 0 \\
\hline I & 7 & 3 & $21 \cdot 333$ & $4 \cdot 333$ & 3 & $1 \cdot 667$ & 0.333 \\
\hline I & 8 & 2 & $16 \cdot 000$ & $2 \cdot 000$ & 2 & $1 \cdot 500$ & 0.500 \\
\hline I & 9 & 2 & $15 \cdot 500$ & 4.500 & 2 & $2 \cdot 000$ & 0 \\
\hline I & 10 & 0 & 0 & 0 & 1 & $1 \cdot 000$ & 0 \\
\hline I \& DI & 1 & 101 & $29 \cdot 099$ & $66 \cdot 510$ & 141 & 0.965 & 0.677 \\
\hline I \& DI & 2 & 54 & $23 \cdot 704$ & 28.401 & 71 & $1 \cdot 338$ & 0.656 \\
\hline I \& DI & 3 & 39 & $22 \cdot 923$ & $28 \cdot 231$ & 46 & $1 \cdot 413$ & 0.337 \\
\hline I \& DI & 4 & 24 & $20 \cdot 292$ & $14 \cdot 303$ & 30 & $1 \cdot 333$ & 0.575 \\
\hline I \& DI & 5 & 12 & $18 \cdot 417$ & $19 \cdot 174$ & 16 & 1.438 & 0.396 \\
\hline I \& DI & 6 & 10 & $17 \cdot 900$ & $8 \cdot 544$ & 10 & 1.900 & $0 \cdot 100$ \\
\hline I \& DI & 7 & 5 & $19 \cdot 800$ & $7 \cdot 700$ & 6 & 1.833 & $0 \cdot 167$ \\
\hline I \& DI & 8 & 5 & $17 \cdot 200$ & $15 \cdot 200$ & 5 & $1 \cdot 800$ & 0.200 \\
\hline I \& DI & 9 & 4 & $15 \cdot 500$ & $15 \cdot 000$ & 4 & $2 \cdot 000$ & 0 \\
\hline I \& DI & 10 & 1 & $18 \cdot 000$ & 0 & 2 & $1 \cdot 500$ & 0.500 \\
\hline DI & 1 & 20 & $28 \cdot 250$ & $75 \cdot 461$ & 29 & $0 \cdot 828$ & 0.576 \\
\hline DI & 2 & 9 & $22 \cdot 222$ & $37 \cdot 444$ & 13 & $1 \cdot 538$ & 0.603 \\
\hline DI & 3 & 9 & $20 \cdot 222$ & $13 \cdot 194$ & 9 & 1.444 & 0.278 \\
\hline DI & 4 & 5 & $20 \cdot 800$ & $6 \cdot 700$ & 8 & $1 \cdot 125$ & 0.696 \\
\hline DI & 5 & 3 & $16 \cdot 667$ & $20 \cdot 333$ & 4 & $1 \cdot 500$ & 0.333 \\
\hline DI & 6 & 3 & $16 \cdot 000$ & $3 \cdot 000$ & 3 & $2 \cdot 000$ & 0 \\
\hline DI & 7 & 0 & 0 & 0 & 1 & $2 \cdot 000$ & 0 \\
\hline DI & 8 & 1 & $15 \cdot 000$ & 0 & 1 & $2 \cdot 000$ & 0 \\
\hline DI & 9 & 1 & $11 \cdot 000$ & 0 & 1 & $2 \cdot 000$ & 0 \\
\hline DI & 10 & 0 & 0 & 0 & 0 & 0 & 0 \\
\hline
\end{tabular}




\begin{tabular}{|c|c|c|c|c|c|c|c|}
\hline \multirow[b]{2}{*}{ Type } & \multirow[b]{2}{*}{ Year } & \multirow[b]{2}{*}{ No. } & \multicolumn{2}{|c|}{ Breeding date } & \multirow[b]{2}{*}{ No. } & \multicolumn{2}{|c|}{ No. chicks fledged } \\
\hline & & & Mean & Variance & & Mean & Variance \\
\hline DI \& D & 1 & 44 & $30 \cdot 205$ & $67 \cdot 701$ & 67 & 0.925 & $0 \cdot 646$ \\
\hline $\mathrm{DI} \& \mathrm{D}$ & 2 & 26 & 24.962 & $40 \cdot 438$ & 35 & $1 \cdot 257$ & 0.550 \\
\hline $\mathrm{DI} \& \mathrm{D}$ & 3 & 20 & $21 \cdot 000$ & $12 \cdot 632$ & 22 & $1 \cdot 318$ & 0.418 \\
\hline $\mathrm{DI} \& \mathrm{D}$ & 4 & 15 & $22 \cdot 067$ & $24 \cdot 638$ & 18 & $1 \cdot 167$ & 0.500 \\
\hline $\mathrm{DI} \& \mathrm{D}$ & 5 & 13 & $20 \cdot 846$ & $24 \cdot 808$ & 14 & $1 \cdot 571$ & 0.418 \\
\hline $\mathrm{DI} \& \mathrm{D}$ & 6 & 9 & $18 \cdot 778$ & $25 \cdot 194$ & 10 & 1.400 & 0.711 \\
\hline DI \& D & 7 & 2 & $18 \cdot 000$ & $8 \cdot 000$ & 4 & $2 \cdot 000$ & 0 \\
\hline $\mathrm{DI} \& \mathrm{D}$ & 8 & 2 & $18 \cdot 500$ & $24 \cdot 500$ & 4 & $1 \cdot 250$ & 0.917 \\
\hline DI \& D & 9 & 1 & $11 \cdot 000$ & 0 & 1 & $2 \cdot 000$ & 0 \\
\hline DI \& D & 10 & 0 & 0 & 0 & 0 & 0 & 0 \\
\hline $\mathrm{D}$ & 1 & 22 & $31 \cdot 227$ & $58 \cdot 470$ & 35 & $1 \cdot 029$ & 0.734 \\
\hline $\mathrm{D}$ & 2 & 17 & $26 \cdot 412$ & $38 \cdot 007$ & 20 & $1 \cdot 050$ & 0.471 \\
\hline $\mathrm{D}$ & 3 & 11 & $21 \cdot 636$ & $12 \cdot 455$ & 13 & $1 \cdot 231$ & 0.526 \\
\hline D & 4 & 10 & $22 \cdot 700$ & $34 \cdot 011$ & 10 & $1 \cdot 200$ & 0.400 \\
\hline $\mathrm{D}$ & 5 & 10 & $22 \cdot 100$ & $20 \cdot 989$ & 10 & $1 \cdot 600$ & 0.489 \\
\hline $\mathrm{D}$ & 6 & 6 & $28 \cdot 167$ & $32 \cdot 167$ & 7 & $1 \cdot 143$ & $0 \cdot 810$ \\
\hline $\mathrm{D}$ & 7 & 2 & $18 \cdot 000$ & 8.000 & 3 & $2 \cdot 000$ & 0 \\
\hline D & 8 & 1 & $22 \cdot 000$ & 0 & 3 & $1 \cdot 000$ & $1 \cdot 000$ \\
\hline $\mathrm{D}$ & 9 & 0 & 0 & 0 & 0 & 0 & 0 \\
\hline $\mathrm{D}$ & 10 & 0 & 0 & 0 & 0 & 0 & 0 \\
\hline
\end{tabular}

TABLE 5

Mean fitnesses of the phases in males and females

$\begin{array}{lcccc}\text { Fitness } & \begin{array}{c}\text { Selective } \\ \text { coefficient }\end{array} & & \text { Fitness } & \begin{array}{c}\text { Selective } \\ \text { coefficient }\end{array} \\ \text { Dark } & 1.3465 & 0 & 1 \cdot 1685 & 0 \\ \begin{array}{l}\text { Intermediate and dark- } \\ \text { intermediate }\end{array} & 1.1366 & 0.156 & 1.2358 & -0.0576 \\ \text { Pale } & 1.1080 & 0.177 & 1.1214 & 0.0403\end{array}$

\section{MAting PREfERENGES FOR THE PHASES}

The selective differences we have demonstrated to exist between the phases of males are determined by the number of offspring the different pairs succeed in fledging. A considerable component of the selection depends on the breeding times of new pairs. This may be defined as sexual selection because it is caused by mating behaviour and not by fertility or the chances of survival. The mechanism which causes the variation in the chances of mating during the breeding season is not of course known. The females may have preferences for mating with dark or intermediate males caused by differences in the males' mating behaviour; or the males may compete with each other through their threat displays. Models of sexual selection are more easily described in terms of mating preferences while being valid for selection by direct competition between males. Mating preferences provide the more likely mechanism, however, and we shall describe four specific models, in these terms. 
The models are used to predict the distributions of breeding times of the phases of males, dark, intermediate (including dark-intermediate) and pale, in new pairs. Fig. 1 and 2 show the actual distributions of males in new pairs and in pairs with 2 or more years of previous breeding experience. The

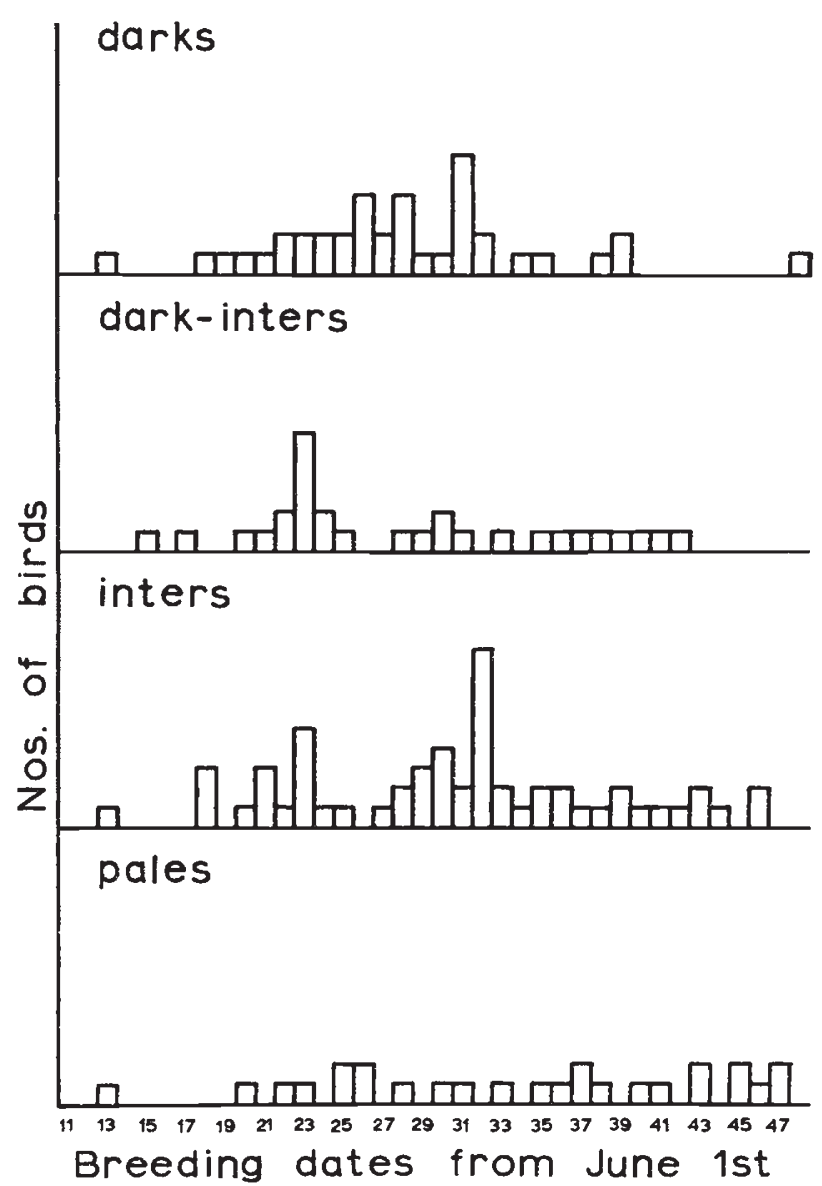

FIG. 1.-The distributions of breeding times of the different phases of males in pairs who are breeding together for the first time.

data from different years have been adjusted to a common median, but this adjustment has only a slight effect. As table 3 proves, in new pairs, pales have a much later mean breeding time with a higher variance than intermediates and darks. But the difference almost disappears with more breeding experience. In fitting the models to the distributions, the breeding times were grouped into weekly intervals as shown in table 6 .

Model 1. This model has already been described in detail by O'Donald $(1973 a)$. It was the model which showed that sexual selection in monogamous birds is necessarily frequency-dependent (O'Donald, 1972b, 1973a). It assumes that there are two phenotypes of male. Some females, who represent a proportion $\alpha$ of all females, have a mating preference for one of the male phenotypes. They always mate with the preferred males if they 
can, but they will mate with the other males if none of their preferred males are available. The remaining females, a proportion $1-\alpha$ of the total, then mate at random with the two male phenotypes. In a given interval of time, $i$, in the breeding season, there is assumed to be a proportion $p_{i}$ of females

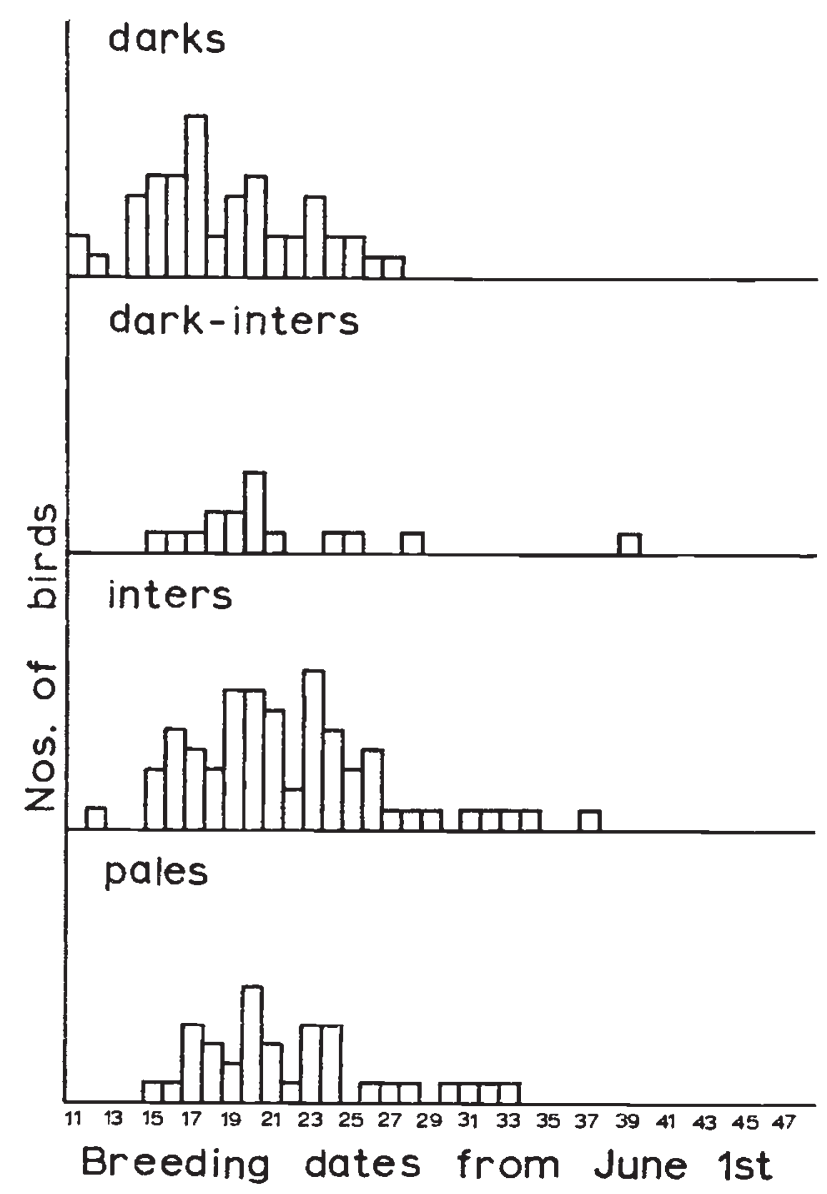

FIG. 2.-The distribution of breeding times of the different phases of males in pairs who have bred together at least 2 years previously.

TABLE 6

Distributions of breeding times of colour phases of males grouped in weekly intervals

\begin{tabular}{|c|c|c|c|c|}
\hline \multirow[b]{2}{*}{$\begin{array}{l}\text { Breeding dates in } \\
\text { weekly intervals }\end{array}$} & \multicolumn{3}{|c|}{ Numbers breeding in interval } & \multirow[b]{2}{*}{ Total } \\
\hline & Pales & $\begin{array}{l}\text { Intermediates and } \\
\text { dark-intermediates }\end{array}$ & Darks & \\
\hline $\begin{array}{l}10-16 \text { June } \\
17-23 \text { June }\end{array}$ & $\begin{array}{l}1 \\
3\end{array}$ & $\begin{array}{r}2 \\
24\end{array}$ & $\begin{array}{l}1 \\
8\end{array}$ & $\begin{array}{r}4 \\
35\end{array}$ \\
\hline $24-30$ June & 6 & 19 & 16 & 41 \\
\hline 1-7 July & 6 & 24 & 10 & 40 \\
\hline 8-14 July & 5 & 15 & 3 & 23 \\
\hline 15-21 July & 5 & 2 & 1 & 8 \\
\hline Total & 26 & 86 & 39 & 151 \\
\hline
\end{tabular}


who are ready to mate: $\alpha p_{i}$ mate with the preferred males and $p_{i}(1-\alpha)$ mate at random among the males who are then still unmated. The weekly intervals given in table 6 were used in the computer program (details given in O'Donald, 1973a) to simulate the actual numbers of the different phases of males. The proportions, $p_{i}$, of females breeding in the weekly intervals were obtained from the weekly totals: the numbers of the different phases simulated in the computer for each weekly interval necessarily add up to the weekly totals in table 6 . The marginal totals are therefore fixed: this is so for all the models.

Model 1 assumes that dark and intermediate males are equally desirable: darks and intermediates were added together to form a class of not-pale males phenotypically preferred as mates to the pales. Table 6 thus becomes a table of $2 \times 6$ values. $\chi^{2}$ was calculated for values of $\alpha$ from $\alpha=0.01$ by steps of 0.01 up to $\alpha=1.0$. Minimum $\chi^{2}$ was obtained at $\alpha=0.52$ when $\chi^{2} \min =0 \cdot 8846$. Since the marginal totals were fixed, 7 degrees of freedom were lost, and an additional degree of freedom was also lost by lumping the numbers in the first and second week. Thus 4 degrees of freedom were left. However, because the numbers of degrees of freedom are greater for the other models, we decided to use $\chi^{2}$ as an approximation to the log likelihood and obtain the 2-unit support limits of the log likelihood. The log likelihood is defined as :

$$
\log L=\Sigma a \log _{e} m
$$

where the values of $a$ are the observed numbers in the classes with expected numbers $m$. Approximately

$$
\Sigma a \log _{e} m=\text { constant }-\frac{1}{2} \chi^{2}
$$

If we subtract $\frac{1}{2} \chi^{2} \min$ from the values of $\frac{1}{2} \chi^{2}$ obtained for the other values of $\alpha$, the particular values for which $\frac{1}{2} \chi^{2}-\frac{1}{2} \chi^{2} \min =2$ will then be the approximate 2-unit support limits of $\alpha$ (Edwards, 1972). These are the values $\alpha=0.25$ and $\alpha=0 \cdot 65$. It would have been better to calculate the log likelihoods directly, but since this was not done in the original calculations the approximation by $\chi^{2}$ was used instead.

Model 2. Like model 1 , this model uses a single parameter $\alpha$ for the proportion of females who have a mating preference. However the females with the preference mate first with dark males; if there are no darks left, they then mate with intermediates, and finally if no intermediates are left either, they mate with pales. The remaining $1-\alpha$ of the females mate at random among remaining unmated males. The minimum $\chi^{2}$ of $12 \cdot 16$ occurs at $\alpha=0 \cdot 12$. The observed numbers were grouped into 13 classes from which 7 degrees of freedom have been lost. The minimum $\chi^{2}$ with 6 degrees of freedom is not quite significant representing a probability of $\mathbf{P}=0.06$. However the values of $\chi^{2}$ are all well outside the approximate 2-unit support limits given by the other models. Model 2 is therefore much the least likely of the four models.

Model 3. In this model a proportion $\alpha$ of the females prefers only darks and mates at random with the other phases if there are no darks left to mate with. Another proportion $\beta$ prefers both darks and intermediates. The $\alpha$ females have the first choice of the available males in each weekly interval of the breeding season. The $\beta$ females then mate at random between the intermediate males and the remaining dark males, and they mate with pales 
when there are no other phases left unmated. The $1-a-\beta$ of the rest of the females mate at random between all phases. This model thus becomes the same as model 1 when $a=0 . \quad \chi^{2}$ has 6 degrees of freedom compared to 4 in model 1. However, when $\alpha=0$, the 2-unit support limits of $\beta$ are $\beta=0.25$ and $\beta=0.65$ - the same limits as those for $\alpha$ obtained from model 1 . $\chi^{2} \min =4.680$ when $\alpha=0.08$ and $\beta=0.40$.

Model 4. In model 4, proportions $\alpha, \beta$ and $\gamma$ of the females prefer dark, intermediate and pale males respectively. Without any of their preferred males to mate with, they mate at random. The remaining $1-\alpha-\beta-\gamma$ of the females mate at random with all phases. O'Donald $(1973 b)$ has given the results of computer simulations of the rate of selection using this model. If the three phases are genetically determined by two alleles so that the dark and pale phases are the two homozygotes and the intermediates are the heterozygotes, then the computer simulations show that a stable equilibrium is reached when the frequency of the dark allele is approximately

$$
p_{e}=\frac{\alpha+\frac{1}{2} \beta}{\alpha+\beta+\gamma}
$$

There is indeed clear evidence that the pales are pure breeding and therefore homozygous, but intermediates and darks may be misclassified as heterozygotes and homozygotes (O'Donald and Davis, 1959). During the course of selection in model 4 , the favoured allele starts with a selective advantage that is more or less additive, the heterozygote being at less of an advantage than the favoured homozygote. But as equilibrium is approached, the overall advantage passes to the heterozygote and maintains the equilibrium. In all the other models, the favoured allele spreads through the population to complete fixation.

In using model 4 to simulate the distributions of breeding times it was assumed that $\gamma=0$. Then $\chi^{2}{ }^{\min }=4.375$ at the point $\alpha=0.18 \beta=0.29$ which gives an equilibrium gene frequency of $p_{e}=0.68$. The minimum $\chi^{2}$ is slightly smaller for this model than for model 3 : model 4 is therefore the model with the greatest likelihood. In both models the 2-unit support limits of the total mating preference $\theta=\alpha+\beta$ are $0 \cdot 18<\theta<0.67$. For model 4 , the support limits for $\beta$ in relation to given values of $\alpha$ give the overall support limits of the equilibrium gene frequency in a range of values $0.832 \geqslant p_{e} \geqslant 0.625$. The actual gene frequency of the dark allele is lower than this. It varies between males and females and is slightly higher in males as we should expect if the theory is true. And it can be estimated in two ways. We can assume that darks and pales are both homozygous and find the total proportion of dark alleles, or we can assume that the genotypes are approximately in the Hardy-Weinberg proportions and calculate the frequency of the pale allele from the proportion of pale phenotypes. The frequencies in females give the following estimates:

$$
\begin{aligned}
& p_{q}=0.475 \text { (assuming darks and pales are homozygous) } \\
& p_{q}=0.518 \text { (by Hardy-Weinberg Law). }
\end{aligned}
$$

In males the corresponding estimates are:

$$
\begin{aligned}
& p_{\delta^{*}}=0.558 \text { (darks and pales homozygous) } \\
& p_{\delta^{*}}=0.586 \text { (Hardy-Weinberg Law). }
\end{aligned}
$$


These estimates were obtained from the numbers of different individuals in the skua colony. There are no significant differences in gene frequency in individuals with different breeding experience.

The gene frequencies do not lie in the range of equilibrium values predicted by model 4. However in the Fair Isle population, equilibrium might not have been reached: the darks may still have been increasing in frequency as a result of selection. Any selective changes are certain to be slow from one year to the next for adult skuas live a long time: a generation may be as long as 10 years. This would explain why the frequencies of the phases remained more or less constant in the 14 years that the colony was

TABLE 7

Relative survival of colour phases from one breeding season to the next

\begin{tabular}{|c|c|c|c|c|c|c|c|c|}
\hline \multirow[b]{2}{*}{ Phase } & \multicolumn{2}{|c|}{ Females } & \multicolumn{2}{|l|}{ Males } & \multicolumn{2}{|c|}{ Both sexes } & & \\
\hline & $\begin{array}{c}\text { Probability } \\
\text { of survival } \\
p_{q}\end{array}$ & $\begin{array}{l}\text { No. } \\
n_{q}\end{array}$ & $\begin{array}{c}\text { Probability } \\
\text { of survival } \\
p_{z}^{*}\end{array}$ & $\begin{array}{l}\text { No. } \\
n_{\hbar^{*}}\end{array}$ & $\begin{array}{c}\text { Probability } \\
\text { of survival } \\
p\end{array}$ & $\begin{array}{l}\text { No. } \\
n\end{array}$ & $\begin{array}{l}\text { Variance } \\
p(1-p)\end{array}$ & $\chi_{1}^{2}$ \\
\hline $\begin{array}{l}\text { Darks } \\
\text { Intermediates and }\end{array}$ & 0.7391 & 46 & 0.8585 & 106 & 0.8224 & 152 & $0 \cdot 1461$ & $3 \cdot 13$ \\
\hline dark-intermediates & s 0.7857 & 224 & 0.7978 & 183 & $0 \cdot 7912$ & 407 & $0 \cdot 1652$ & 0.09 \\
\hline Pales & $0 \cdot 8202$ & 89 & 0.7755 & 49 & 0.8043 & 138 & $0 \cdot 1574$ & $0 \cdot 40$ \\
\hline Total & 0.7883 & 359 & 0.8136 & 338 & $0 \cdot 8006$ & 697 & $0 \cdot 1597$ & $0 \cdot 70$ \\
\hline
\end{tabular}

For each phase $\chi_{1}^{2}$ is calculated by the formula

$$
\chi_{1}^{2}=\frac{\left(p_{q}-p\right)^{2}}{\left(\frac{p(1-p)}{n_{\subsetneq}}\right)}+\frac{\left(p_{\ddagger}-P\right)^{2}}{\left(\frac{p(1-p)}{n_{\ddagger}}\right)^{-}}
$$

The heterogeneity in mortality in phases of different sex is given by

$$
\chi_{2}^{2}=2 \cdot 92 \text {. }
$$

studied. At the same time it is possible that natural selection resulting from differences in mortality between the phases maintains the equilibrium at its present frequency by opposing the sexual selection. As O'Donald (1973a) has shown, such equilibria are stable provided the mating preferences are not shared by more than 40-45 per cent of the females. An equilibrium maintained by the opposing forces of natural and sexual selection is stable only if the sexual selection is negatively frequency dependent. This is true of mating preferences involving no more than about 45 per cent of females. In both models 3 and 4, mating preferences involving only 19 per cent of the females are allowable within the 2-unit support limits. There is evidence given in table 7 of differences in mortality between the phases but the numbers of individuals are too few for the differences to be significant. If they were significant, the differences in mortality would certainly give rise to natural selection that could balance the sexual selection at a point of stable equilibrium.

The four models compared. As we have shown, model 2 is the least likely, while model 4 is slightly more likely than model 3. Model 2 can certainly be rejected in comparison with the others because all its values of $\chi^{2}$ lie well outside the 2-unit support limits of models 3 and 4. Fig. 3 shows these approximate support limits, together with the point of maximum likelihood 
for each model. By collecting more data on the Arctic skuas of Fair Isle, we hope to obtain a closer set of limits that will permit more precise predictions to be made for comparison with the observations.

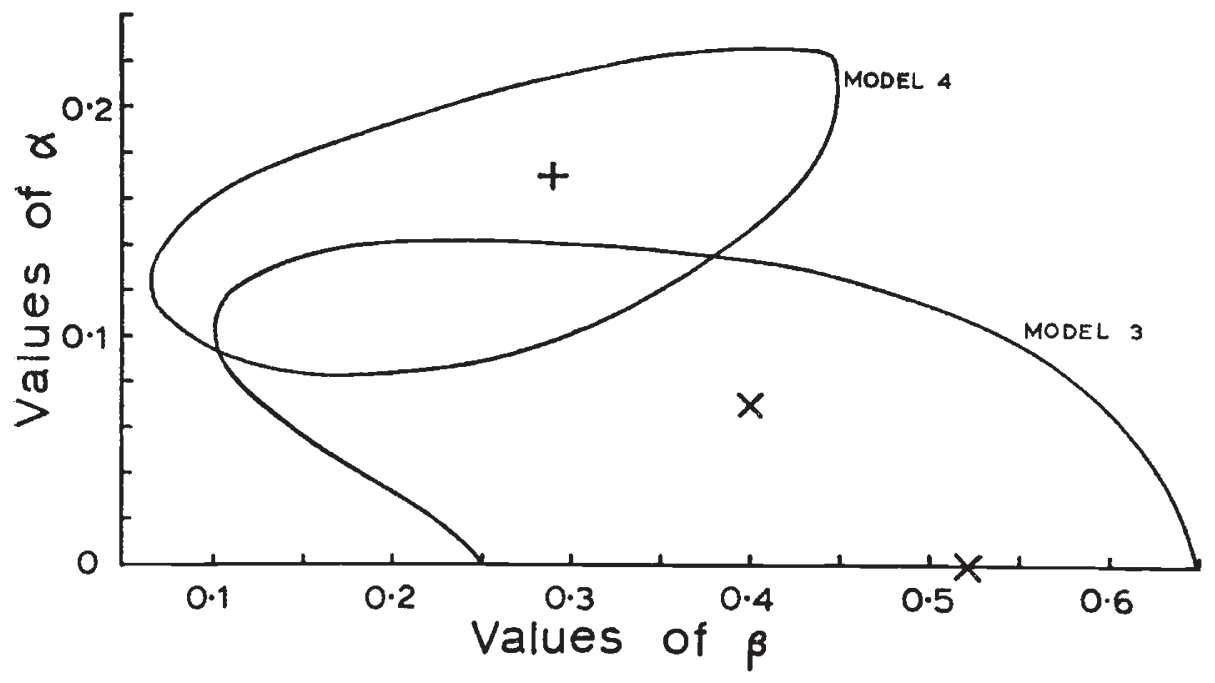

FIG. 3.-The approximate support limits of female mating preferences for models 3 and 4 . Values of $\alpha$ and $\beta$ lying inside the closed areas are within the 2-unit support limits. The symbol " + " marks the point of minimum $\chi^{2}$ in model 4 . The symbols " $x$ " mark the points of minimum $\chi^{2}$ in model 3 when $\alpha>0$ and $a=0$.

\section{REFERENGeS}

BERRY, R. J., AND DAVIS, P. E. 1970. Polymorphism and behaviour in the Arctic Skua (Stercorarius parasiticus (L.)). Proc. R. Soc. Lond. B, 175, 255-267.

DARWIN, c. 1871. The Descent of Man and Selection in Relation to Sex. John Murray, London. EDWARDS, A. W. F. 1972. Likelihood. The University Press, Cambridge.

O'DONAlD, P. 1962. Ecology and evolution in the Arctic Skua. Ph.D. thesis, University of Cambridge.

o'DONALD, P. 1972a. Natural selection of reproductive rates and breeding times and its effect on sexual selection. Am. Nat., 106, 368-379.

o'donald, P. 1972b. Sexual selection by variations in fitness at breeding time. Nature, Lond., 237, 349-351.

o'Donald, P. 1972c. Sexual selection for colour phases in the Arctic Skua. Nature, Lond., 238, 403-404.

o'DONALD, P. 1973a. Frequency-dependent sexual selection as a result of variations in fitness at breeding time. Heredity, 30, 351-368.

o'Donald, P. 1973b. Polymorphisms maintained by sexual selection in monogamous species of birds. Heredity, 32, 1-10

O'DONALD, P., AND DAVIS, P. E. 1959. The genetics of the colour phases of the Arctic Skua. Heredity, 13, 481-486.

williamson, K. 1965. Fair Isle and its Birds. Oliver \& Boyd, Edinburgh. 